\title{
Impact of Obstructive Sleep Apnoea on Rate of Dysrrhythmia and Outcome in Stroke Admissions on the Medical Service of Jos University Teaching Hospital
}

\author{
Basil Nwaneri Okeahialam*, Patrick Oyigebe Idoko \\ Cardiology Sub-Unit 1, Department of Medicine, Jos University Teaching Hospital, Jos, Nigeria
}

Email address:

basokeam@yahoo.com (B. N. Okeahialam)

${ }^{*}$ Corresponding author

\section{To cite this article:}

Basil Nwaneri Okeahialam, Patrick Oyigebe Idoko. Impact of Obstructive Sleep Apnoea on Rate of Dysrrhythmia and Outcome in Stroke Admissions on the Medical Service of Jos University Teaching Hospital. American Journal of Internal Medicine.

Vol. 9, No. 3, 2021, pp. 138-141. doi: 10.11648/j.ajim.20210903.15

Received: April 25, 2021; Accepted: May 14, 2021; Published: May 31, 2021

\begin{abstract}
Obstructive sleep apnoea (OSA) is said to be associated with stroke and can be modulated to advantage. Given its impact on atrial fibrillation (AF), a predictor of severity and poor stroke outcome, we decided to study the relationship of OSA with arrhythmias and outcome in stroke patients admitted on our service. Stroke patients admitted and confirmed by neuroimaging were examined physically, underwent 24 hour Holter monitoring and assessed for severity, dependency and survival status by 4 weeks after admission. They had arterial blood saturation checked between $10 \mathrm{pm}$ and $2 \mathrm{am}$. Saturation $<90 \%$ defined OSAS and it was correlated with presence of arrhythmias, severity of stroke and outcome measures. Ninety four patients $(52 \mathrm{M}, 42 \mathrm{~F})$ were enrolled. Ten, $6 \mathrm{M} 4 \mathrm{~F}$ had OSA with a mean age of $56.00 \pm 16.80$ years. AF was more associated with OSA to a statistically significant extent (chi-square $=7.453, \mathrm{p}=0.006$ ). When it comes to mortality or whether patient was still on admission or had been discharged by 4 weeks, presence of OSA made an obvious difference. (chi-square=16.202. $\mathrm{p}=0.001$ ). Those with OSA were more dependent 4 weeks after admission and had more severe stroke, but the difference missed statistical significance. In conclusion, OSA in stroke patients is fraught with a high risk of arrhythmias in which presence strokes are more severe with poorer outcomes. Appropriate management of OSA in patients at risk of stroke or after the ictus is bound to mitigate the burden and consequences of stroke.
\end{abstract}

Keywords: Obstructive Sleep Apnea, Arrhythmias, Stroke, Severity, Outcome

\section{Introduction}

Obstructive sleep apnoea (OSA) is a common sleep disorder resulting from recurrent collapse and intermittent obstruction of the upper airway in the course of sleep [1]. It impairs quality of life by fragmented sleep of poor quality, daytime somnolence, increased tendency to accidents and depression [2]. As reported in a meta-analysis [3] and a study published recently by Bonsignore et al, it is significantly associated with stroke and cardiovascular diseases [4]; being a higher risk for atherosclerosis indexed by carotid intima media thickness (CIMT [5]. Thus, it is considered a potential treatment target to improve outcome severity. On the other hand, stroke is a leading cause of cardiovascular disease morbi-mortality [6] with huge economic burden [7]. Sadly it has increased over time in our environment from the prevalence of $0.58 / 1000$ two decades ago [9] to the current doubling of figures as reported by Danesi et al [10].

Given the impact of OSA and cardiac dysrhythmias (especially atrial fibrillation), and the role of atrial fibrillation (AF) in severity and outcomes of stroke [11], we decided to study the place of OSA in patients admitted under our care with stroke. If OSA is seen to play a significant role, it would be possible to reduce stroke burden on patients and health systems by manipulating OSA. 


\section{Methods}

Between September 2016 and January 2018 as part of a larger study approved by the hospital Research and Ethics committee titled Electrocardiographic assessment of arrhythmic burden in stroke patients admitted to Jos University Teaching Hospital, we measured the arterial oxygen saturation of all admitted adult stroke patients while they were asleep between $10.00 \mathrm{pm}$ and $2.00 \mathrm{am}$. All patients or caregivers (where patients were unable given their clinical state) gave written informed consent. The diagnosis of stroke was made clinically and confirmed by brain imaging (Brain Computerised Tomographic Scan). Modified Rankin Scale score was used to assess severity of stroke. None of the patients was on any arrhythmia-modifying drug at the time. Basic demographic characteristics were documented.

A BLT M700 hand held pulse oximeter was used to measure their arterial oxygen saturation $(\mathrm{SpO} 2)$; by applying it on the index finger of the patients for about two minutes. This was after being tested on the researcher. After the two minutes period, the most stable oxygen saturation recording was noted and recorded. SpO2 less than $90 \%$ in room air was used to define OSA. It has been said the strongest OSA related predictor of cardiovascular events is sleep time spent with SpO2 less than 90\% [12]. All patients underwent 24 hour continuous electrocardiographic monitoring using a Holter monitor (Continuous ECG machine; C. Net 5000 Cardionetics) with Cardionetics Connect software; which analysed and summarized the recordings including that of arrhythmias.

All patients were re-assessed at 4 weeks to determine if they were still on admission, if they were dead and if dependent. Modified Rankin Scale (MRS) score at 4 weeks was used to determine dependence; as has been the standard [13].

STATISTICS: Data were analysed using SPSS version 23. Continuous variables were expressed as mean \pm SD and categorical variables as proportions. The chi-square test was used to compare proportions while the student- $t$ test was used to compare means of groups. Where appropriate Analysis of Variance ANOVA was applied to test for association. A p value $<0.05$ determined statistical significance.

\section{Results}

A total of 94 patients were studied; 52 males and 42 females. Out of the $94,84(89.4 \%)$ had $\mathrm{SpO} 2 \geq 90 \%$. Only $10(10.6 \%)$ had $\mathrm{SpO} 2<90 \%$; and hence could be said to have OSA. Of this 10, 6 were male and 4 females. The mean age of those qualifying as OSA was $56.00 \pm 16.80$ years; while that for those without OSA was $50.76 \pm 16.13$ years. There was no statistically significant difference between both groups as regards age $(t=0.966 ; p=0.336)$. Pertaining gender, there was also no significant relationship (chi-square $=1.064$; $\mathrm{p}=0.302$ ).

The cardiac arrhythmia, atrial fibrillation (AF) was more associated with OSA than not; to a statistically significant extent (chi-square=7.453, $\mathrm{p}=0.006$ ). See Table 1 .
Table 1. Association between AF and SpO2 status.

\begin{tabular}{lllll}
\hline AF status & SpO2 $<\mathbf{9 0 \%}$ & SpO2 $\geq \mathbf{9 0 \%}$ & Chi-square & p \\
\hline Yes & $4(33.3)$ & $8(66.7)$ & 7.453 & 0.006 \\
No & $6(10.6)$ & $76(92.7)$ & & \\
Total & $10(10.6)$ & $84(89.4)$ & & \\
\hline
\end{tabular}

Data are proportions (percentages)

Though more dependent 4 weeks after admission, the difference between those with and without OSA narrowly missed statistical significance (chi-square $=3.609, p=0.057$ ) Similarly, although the severity of stroke in those with OSA was greater than among those without OSA, the difference did not attain statistical significance (chi-square=2.328, $\mathrm{p}=0.127)$.

When it comes to mortality or whether patient was still on admission or had been discharged by 4 weeks, presence of OSA made an obvious difference. They were worse off to a statistically significant extent. (chi-square $=16.202$. $\mathrm{p}=0.001$ ). See Table 2 .

Table 2. Association between SpO2 status and mortality or admission status 4 weeks after admission.

\begin{tabular}{lllll}
\hline $\begin{array}{l}\text { Admission status } \\
\text { at } \mathbf{4} \text { weeks }\end{array}$ & SpO2 $<\mathbf{9 0 \%}$ & $\begin{array}{l}\text { SpO2 } \geq \\
\mathbf{9 0 \%}\end{array}$ & Chi-square & P \\
\hline Discharged & $2(5.0)$ & $38(95.0)$ & 16.202 & 0.001 \\
Still on admission & $1(5.9)$ & $16(94.1)$ & & \\
Dead & $5(50.0)$ & $5(50.0)$ & & \\
Total & $8(11.9)$ & $59(88.1)$ & & \\
\hline
\end{tabular}

Data are proportions (percentages)

\section{Discussion}

OSA, here defined as $\mathrm{SpO} 2<90 \%$ was significantly associated with AF; the commonest arrhythmia encountered in clinical practice [14]. Cardiac arrhythmias like AF have been shown to be common in patients with OSA $[15,6]$. OSA is characterized by episodes of apnoea/hypopnoea which increase severity of hypoxaemia [17] that trigger AF. The risk of an episode of AF is higher after an episode of apnoea/hypopnea by 18 times than during periods of normal breathing [17]. This intermittent hypoxaemia brings AF about via sympathetic activation and cardiovascular variability [3].

Our study has shown that having OSA was significantly associated with the arrhythmia AF. Kanagala et al in 2003 [18] had shown that OSA was associated with recurrence of AF; and so did Mooe $T$ et al [19] in a paper on sleep disordered breathing predicting AF after coronary interventions.. Again due to intermittent hypoxaemia in OSA, intrathoracic pressure changes repeatedly leading to extensive mechanical stress on the cardiac and vascular walls. With the repeated arousal of OSA, carbon dioxide retention and the corresponding sympathetic overdrive results in wide blood pressure excursions [20]. OSA with its repeated arousals that increase sympathetic activity while depressing parasympathetic activity results in tachycardia and elevated blood pressure [21]. In this study (result not shown), sinus tachycardia was the commonest arrhythmia seen in the stroke patients.

OSA has been suggested to be a significant predictor of 
serious adverse outcome after a stroke. In the work of Xie et al [3], it also significantly increased the risk of stroke. This is not surprising as hypertension, a cardinal risk factor of stroke has been shown to have a high likelihood of resistance in the face of OSA [22]. In OSA the blood pressure profile is that of "non-dipping" [23]. All these increase the chance of the individual suffering a stroke. Though not in humans, Lloyd et al have shown that OSA accelerates onset of cerebrovascular diseases as well as breaking down the blood-brain barrier [24]. In this study severity of stroke turned out to be higher in those with OSA though not to a statistically significant extent. Dependency, a reflection of severity was also higher though not significantly. This lack of statistical significance may be because of sample size or utilizing only $\mathrm{SpO} 2$ to diagnose OSA. AF, which is common in OSA, leaves $20 \%$ of stroke patients induced by it, dying within 1 year; and $60 \%$ being made dependent by a disability [25]. Mortality in our stroke patients with OSA was significantly higher than those without (See Table 2). Increased risk of sudden death during sleep has been reported in patients with OSA [26], and is thought to be related to cardiac arrhythmias [27, 28].

It must be stated that polysomnography is the gold standard for assessing OSA. We did not have it at our disposal, and had to rely only on $\mathrm{SpO} 2$, which is a surrogate marker of OSA. Data from sleep studies would have made our study more robust, and may have lifted those associations that tended to, but missed statistical significance clearly so.

\section{Conclusion}

OSA in stroke patients is fraught with a high risk of arrhythmias especially tachy-arrhythmias Whereas $40 \%$ of those with OSA had AF, only $9.5 \%$ of those without OSA had AF. OSA in the presence of strokes gives more severe presentation with poorer outcomes. Appropriate management of OSA in patients at risk of stroke is bound to mitigate the burden and consequences of stroke [29]. Even after stroke, those found to have OSA may have better outcomes if attention is paid to their periodic hypopnoeas.

\section{Conflict of Interest}

The authors have NO conflict of interest to declare.

\section{Financial Support}

No external funding was received.

\section{Author Contributions}

Patrick Idoko-Examined patients, undertook the Holter monitoring of patients, supervised $\mathrm{SpO} 2$ measurements, and analysed data.

Basil Okeahialam-Conceived the study and wrote up the manuscript.

\section{Acknowledgements}

We appreciate our unit doctors who on occasions assisted with $\mathrm{SpO} 2$ measurements. The co-operation of patients and their caregivers is also appreciated.

\section{References}

[1] Maeder MT, Schoch OD, Rickli H. A clinical approach to obstructive sleep apnoea as a risk factor for cardiovascular disease. Vasc. Health. Risk Mgt. 2016; 12: 85-103.

[2] Jordan AS, McSharry DG, Malhotra A. Adult obstructive sleep apnoea. Lancet. 2014; 383 (9918): 736-747.

[3] Xie W, Zheng F, Song X. Obstructive sleep apnoea and serious adverse outcomes in patients with cardiovascular and cerebrovascular disease. A PRISMA-compliant systematic review and meta-analysis. Medicine. 2014; 93 (29): 1-8.

[4] Bonsignore MR, Baiamonte P, Mazzuca E, Castrogiovanni A, Marrone O. Obstructive sleep apnoea and co-morbidities: a dangerous liaison. Multidisciplinary Resp Med. 2019. 14 (6). Httpps://doi.org/10.1186/s40248-019-0172-9.

[5] Ciccone MM, Schicchitano P, Mitacchione G, Zito A, Gesualdo M, Caputo P et al. Is there a correlation between OSAS duration/severity and carotid intima media thickness. Respir Med. 2012; 106 (5): 740-746. Doi: 10.1016/jrmed.20011.12.016.

[6] Kozub E. Community stroke prevention programme. An overview. J. NeuroScience Nursing. 2010; 42 (3): 143-149.

[7] Rosamond W, Flegal K, Furie K, Go A, Greenlund K, Haase $\mathrm{N}$ et al. Heart disease and Stroke statistics; 2008 update: A report from the American Heart Association Statistics Committee and Stroke Statistics sub-committee. Circulation. 2008; 117 (4): e25-e146.

[8] Birabi B, Oke K, Dienye P, Okafor UC. Cost burden of post stroke condition in Nigeria: a pilot study. Glob J. Health Sci. 2012; 4 (6): 17-22.

[9] Osuntokun B, Adeuja A, Schoenberg B, Bademosi O, Nottidge VA, Olumide AO et al. Neurological disorders in Nigerian Africans: a community based study. Acta Neurol Scand. 1987; 75 (1): 13-21.

[10] Danesi M, Okubadejo N, Ojini F. Prevalence of stroke in an urban mixed-income community in Lagos Nigeria. Neuroepid. 200728 (4): 216-223.

[11] Hahne K, Monnig G, Samol A. Atrial fibrillation and silent strokes: links, risks and challenges, Vasc Health Risk Mgt. 2016; 12: 65-74.

[12] Kandzerska T, Gershon AS, Hawker G, Leung RS, Tomlinson G. Obstructive sleep apnoea and risk of cardiovascular events and all-cause mortality. A decade long historical cohort study. PLOS Medicine. 2014; 11 (2): e 1001599. Doi: 10.1371/journal.pmed.1001599.

[13] Zhao Y, Zou C, Wang C, Zhang Y, Wang S. Long term outcome after stroke in elderly patients with atrial fibrillation. A hospital based study in China. Front. Aging Neurosci. 2016; 8: 56.

[14] Gutierrez C, Blanchard DG. Atrial fibrillation: Diagnosis and treatment. Am. Fam. Physician. 2011; 83 (1): 61-68. 
[15] Bertolami A, Gonzaga C, Amodeo C. Cardiac function and hypertension in patients with obstructive sleep apnoea. Res. Rep. Clin Cardiol. 2014; 45: 189-197.

[16] Geovanini GR, Lorenzi-Filho G,. Cardaiac rhythm disorders in obstructive sleep apnoea. J. Thoac. Dis. 2018. (Suppl 34): S4221-4230.

[17] Monahan K, Stofer-Issar A, Mehra R, Shahar E, Mittlemann M, Rottman $\mathrm{J}$ et al. Triggering of nocturnal arrhythmias by sleep disordered breathing events. J Am Coll Cardiol. 2009; 54 (19): 1797-1804.

[18] Kanagala R, Murali NS, Friedman PA, Ammash NM, Gersh BJ, Baalman KV et al. Obstructive sleep apnea and the recurrence of atrial fibrillation. Circulation. 2003. 107 (20): 2589-2594.

[19] Mooe T, Franklin KA, Wiklund U, Rabben T, Holmström K. Cardiac rhythm in patients with sleep-disordered breathing and coronary artery disease. Scand Cardiovasc J. 2000.34 (3): 272-276.

[20] Kohler M, Stradling JR. Mechanisms of vascular damage in obstructive sleep apnoea. Nat. Rev. Cardiol. 2010; 7: 677-685.

[21] Somers VK, Javaheri S. Cardiovascular effects of sleep related breathing disorders. In: Roth T, Demet WC (eds). Principles and practice of sleep Medicine. $5^{\text {th }}$ edi. St Louis MO. USA. Elsevier Sanders. 2011: 1370-1380.

[22] Calhoun DA, Jones D, Textor S, Goff DC, Murphy TP, Toto $\mathrm{RD}$ et al. Resistant hypertension diagnosis evaluation and treatment: a scientific statement from the American Heart Association Professional Education Committee of the Council for High Blood Pressure Research. Circulation. 2008; 117 (25): e510-e526.
[23] O’Brien E, Parchi G, Steigon G, Asman R, Beilin L, Bilo G et al. European Society of Hypertension position paper on ambulatory blood pressure monitoring. J Hypertens. 2013; 31: $1731-1768$.

[24] Lloyd EE, Durgan DJ, Martini SR, Bryan RM. Pathological effects of obstructive sleep apneas during the sleep cycle in an animal model of cerebral small vessel disease. Hypertens. 2015; 66: 913-917. 10.1161/HYPERTENSIONAHA.115.05764.

[25] Tawfik A, Bielechi JM, Krahn M, Dorian P, Hoch JS, Boon H et al. Systematic review and network meta-analysis of stroke prevention treatments in patients with atrial fibrillation. Clin Pharm Advances and Applications. 2016; 8: 93-107.

[26] Gami AS, Howard DE, Olsen EJ, Somers VR. Day-night pattern of sudden death in obstructive sleep apnoea. New Eng J Med. 2005; 352 (12): 1206-1214.

[27] Gami AS, Hodge DO, Herges RM, Olsom DJ, Nykodim J, Kara $\mathrm{T}$ et al. Obstructive sleep apnoea obesity and the risk of incident atrial fibrillation. J. Am Coll. Cardiol. 2007; 49 (5): 565-571.

[28] Mehra R, Benjamin EJ, Shahar E, Gottlieb DJ, Nawabit R, Kirchna HL et al. Association of nocturnal arrhythmias with sleep discordant breathing. The Sleep Heart Health Study. Am J Respir Crit Care Med. 2006; 173 (8): 910-916.

[29] Jehen S, Farag M, Zizi F, Pandi-Perumai SR, Chung A, Truong a et al. Obstructive sleep apnoea and stroke. Sleep Med Disord. 2018; 2 (5): 120-125. 